\title{
Coordinate and categorical judgements in spatial imagery. An fMRI study.
}

Citation for published version (APA):

Trojano, L., Grossi, D., Linden, D., Formisano, E., Goebel, R. W., Cirillo, S., Elefante, R., \& Di Salle, F. (2002). Coordinate and categorical judgements in spatial imagery. An fMRl study. Neuropsychologia, 40, 1666-1674. https://doi.org/10.1016/S0028-3932(02)00021-0

Document status and date:

Published: 01/01/2002

DOI:

10.1016/S0028-3932(02)00021-0

Document Version:

Publisher's PDF, also known as Version of record

\section{Please check the document version of this publication:}

- A submitted manuscript is the version of the article upon submission and before peer-review. There can be important differences between the submitted version and the official published version of record.

People interested in the research are advised to contact the author for the final version of the publication, or visit the DOI to the publisher's website.

- The final author version and the galley proof are versions of the publication after peer review.

- The final published version features the final layout of the paper including the volume, issue and page numbers.

Link to publication

\footnotetext{
General rights rights.

- You may freely distribute the URL identifying the publication in the public portal. please follow below link for the End User Agreement:

www.umlib.nl/taverne-license

Take down policy

If you believe that this document breaches copyright please contact us at:

repository@maastrichtuniversity.nl

providing details and we will investigate your claim.
}

Copyright and moral rights for the publications made accessible in the public portal are retained by the authors and/or other copyright owners and it is a condition of accessing publications that users recognise and abide by the legal requirements associated with these

- Users may download and print one copy of any publication from the public portal for the purpose of private study or research.

- You may not further distribute the material or use it for any profit-making activity or commercial gain

If the publication is distributed under the terms of Article $25 \mathrm{fa}$ of the Dutch Copyright Act, indicated by the "Taverne" license above, 


\title{
Coordinate and categorical judgements in spatial imagery. An fMRI study ${ }^{\text {is }}$
}

\author{
Luigi Trojano $^{\mathrm{a}, *}$, Dario Grossi ${ }^{\mathrm{b}}$, David E.J. Linden ${ }^{\mathrm{c}, \mathrm{d}}$, Elia Formisano ${ }^{\mathrm{e}}$, Rainer Goebel ${ }^{\mathrm{e}}$, \\ Sossio Cirillo $^{\mathrm{f}}$, Raffaele Elefante ${ }^{\mathrm{f}}$, Francesco Di Salle ${ }^{\mathrm{f}}$ \\ a Salvatore Maugeri Foundation, IRCCS, Institute of Telese, Loc. S. Stefano in Lanterria, 82037 Telese Terme, BN, Italy \\ ${ }^{\mathrm{b}}$ Department of Psychology, Second University of Naples, via Vivaldi 43, 81100 Caserta, Italy \\ ${ }^{\mathrm{c}}$ Department of Neurology Klinikum der Johann Wolfgang Goethe-Universität, Schleusenweg 2-16, 60528 Frankfurt, Germany \\ ${ }^{\mathrm{d}}$ Max-Planck-Institut für Hirnforschung, Deutschordenstrasse 46, 60528 Frankfurt, Germany \\ ${ }^{e}$ Department of Neurocognition/Psychology, Universiteit Maastricht, Postbus 616, 6200MD Maastricht, The Netherlands \\ ${ }^{\mathrm{f}}$ Department of Neurological Sciences, Division of Neuroradiology, Federico II University, Nuovo Policlinico, Via S. Pansini 5, 80131 Naples, Italy
}

Received 6 February 2001; received in revised form 16 January 2002; accepted 16 January 2002

\begin{abstract}
We aimed at verifying whether the hemispheric specialisation for categorical/coordinate spatial judgements also applies to the spatial imagery domain by the use of whole-brain fMRI. In a block-design experiment we used the "coordinate" mental clock test, contrasting it with a "categorical" task applied to the same clock stimuli; as a control task we used a syllable counting task requiring a verbal-phonological judgement on the same material of the two imagery tasks. Our results showed that categorical and coordinate spatial judgements on imagined stimuli rely on the activation of a set of cortical areas, centred upon the superior parietal lobule (SPL) bilaterally. These regions, together with other parietal and prefrontal areas, showed a pattern of relative lateralization, with the left hemisphere being mainly activated during the categorical task and the right in the coordinate task. These data confirm the strong involvement of the SPL in spatial processing. Moreover, our findings suggest that different interconnected neural networks are activated to comply with specific test requirements, giving rise to functional imaging patterns compatible with psychological theories on hemispheric specialization. (C) 2002 Elsevier Science Ltd. All rights reserved.
\end{abstract}

Keywords: Spatial transformations; Coordinate and categorical judgements; Mental imagery; Parietal lobe; Functional magnetic resonance imaging; Blood oxygen level-dependent signal

\section{Introduction}

The brain can compute spatial relationships between the observer and the surrounding objects to allow precise and quick decisions and actions. Current theoretical models of spatial processing foresee that two different kinds of spatial encoding proceed in parallel. The former is able to encode discrete (categorical) spatial relations, those easily described by verbal locatives (e.g. one object is on the left/right or above/below with respect to another); the latter encodes metric (coordinate) spatial relations, that is represents precise, quantitative aspects of the spatial relationships [16]. Both cerebral hemispheres participate in spatial processing of visual input, but each seems to be specialised in a particular kind of spatial processing. The left hemisphere would be

\footnotetext{
Paper presented at the International Neuropsychological Symposium, Thun 21-26 June, 2000.

* Corresponding author. Tel.: +39-824-909111; fax: +39-824-909611.

E-mail address: 1trojano@fsm.it (L. Trojano).
}

relatively faster than the right at encoding "categorical" spatial relations, while the right hemisphere would be superior at encoding metric (coordinate) spatial relations $[4,16]$. This hypothesis has received support from many tachistoscopic studies with divided visual field tasks on normal subjects [22], although the matter is still open to debate and several factors may affect lateralization results [5,25,33].

It has been suggested that the categorical/coordinate dichotomy may apply also to the visual imagery domain [17]. Michimata [20] demonstrated a significant right hemisphere advantage in a coordinate task both in visual perception and imagery (to judge whether the long and short hands of a clock formed an angle smaller or larger than $60^{\circ}$ at a given time), and a non-significant left hemisphere advantage in a categorical task in both modalities (to indicate whether the long and short hands of a clock were above or below the horizontal midline of the dial at a given time). The analysis of single subjects' reaction times showed some inconsistencies, but on a group basis Michimata's findings suggested a correspondence between cognitive processes involved in visual 
perception and imagery with a dominant role of the right hemisphere for coordinate judgements in both domains, and no clear hemispheric specialisation for categorical judgements [20]. The right hemisphere superiority in extracting spatial (coordinate) information from mental images has also been demonstrated in a study on dot localisation [9], but in this case patterns of lateralization did not overlap in the perception and the imagery domains.

The development of modern neuroimaging techniques has provided new tools to afford the lateralization issue. Using functional magnetic resonance imaging (fMRI) in an experiment on visual perception, Baciu et al. [2] demonstrated a left hemisphere preference in a categorical task (to judge whether a dot was presented above or below a horizontal line) and a stronger activation of the right hemisphere in a coordinate task (to judge whether the distance between a dot and a bar was within a reference distance). These findings would confirm Kosslyn's [16] theory in the visual perception domain.

Using a behaviourally controlled mental imagery paradigm (requiring a coordinate imagery comparison of two clocks in the absence of visual stimulation), we recently demonstrated robust activation in posterior parietal cortex in both hemispheres by fMRI [31]. We could thus identify the subset of spatial analysis-related activity that is involved in spatial operations on mental images and provide evidence for a specific convergence of the pathways of imagery and visual perception within the parietal lobes. While we found a slight prevalence of left posterior parietal cortex activation in the spatial coordinate imagery task, our findings were not conclusive for the lateralization issue.

In the present paper we aimed at verifying whether the hemispheric specialization for categorical/coordinate judgements also applies to the spatial imagery domain by the use of whole-brain fMRI. We used again the coordinate mental clock test, contrasting it with a categorical task applied to the same clock stimuli.

\section{Method}

\subsection{Participants}

We recruited seven right-handed post-graduate students (four male, three female; mean age 29 years; range 23-34), who gave their written informed consent to participate in the study. None of the subjects was taking any medication or was affected by neurological or psychiatric conditions. All of them were unaware of the purposes and predictions of the experiment at the time of testing.

\subsection{Experimental paradigm}

\subsubsection{Coordinate task}

Subjects were asked to imagine two analogue clock faces based on the times that were presented verbally by the examiner (e.g. 9:30 and 10:00; inter-stimulus interval $=1 \mathrm{~s}$ ), and to judge at which of the two times the clock hands form the greater angle. We selected 48 pairs of times, involving only half-hours (i.e. 7:30) or hours (i.e. 9:00). The clock faces were balanced for the side on which the hands had to be imagined and presented in pseudo-random order. Subjects had to push a button with their right index finger if the hands of the first clock formed the greater angle, or their right middle finger for the second.

\subsubsection{Categorical task}

Subjects were asked to imagine an analogue clock face showing the time verbally presented by the examiner. After each verbal presentation of a time, subjects heard a cue indicating one half of the clock face (left, right, upper or lower; inter-stimulus interval $=1 \mathrm{~s}$ ) and they had to judge whether both hands lay in the cued half of the clock face (congruent trials) or not (non-congruent trials). For this task we selected 48 times, half of which were congruent with the respective cue (e.g. 10:10-upper; 1:20-right), while the remaining were not (e.g. 9:40-upper; 7:20-left). For non-congruent trials, times were chosen that would correspond to a different cue. This choice was made to discourage subjects to resort to verbal labels, and compel them to form mental images in response to all clock stimuli. Subjects had to push a button with their right index finger for "yes" decisions (congruent trials), or their right middle finger for "no" decisions.

\subsubsection{Control (phonological) task}

We asked subjects to count the syllables of each of 48 auditorily presented pairs of times and to report whether the total syllable number was odd or even. In this syllable counting condition, material, presentation and response modality were the same as in the imagery tasks, but here a verbal-phonological judgement was required that was matched for response time with the coordinate imagery task [30].

\subsection{Procedure}

Three sessions of 72 measurements were conducted for each subject. Within each session, the three conditions were alternated in blocks of eight trials (one trial per measurement, eight measurements per block) and separated by blocks of four "resting" measurements. The categorical and the coordinate conditions were alternated in the sequence of stimulation conditions, with the phonological task always following the two imagery tasks. In all the conditions, the inter-trial interval was $5 \mathrm{~s}$ (one trial per scan), and every trial block was preceded by the appropriate instruction. Subjects' responses were registered by an optic fibre answer box and analysed for accuracy and response times. Mean correct reaction times for each subject were used for the speed of performance analysis. Because of the low number of subjects, statistical analysis was performed by non-parametric methods (Kruskal-Wallis test for three-group comparisons). 
Subjects were asked to keep their eyes open during the scanning session and foveate a fixation cross in order to avoid eye movements. Control scans with infrared eyetracking were performed on two subjects (see Section 2.4).

\subsection{Apparatus}

\subsubsection{MR hardware and sequences}

Experiments were performed at the Klinikum der Johann Wolfgang Goethe-Universität, in Frankfurt, Germany. The MR scanner used for imaging was a $1.5 \mathrm{~T}$ whole body superconducting system (Magnetom Vision, Siemens Medical Systems, Erlangen, Germany) equipped with a standard head coil, an active shielded gradient coil $(25 \mathrm{mT} / \mathrm{m})$ and echo planar (EPI) sequences for ultra-fast MR imaging.

For functional imaging, we used a 'bold' sensitive single shot EPI sequence (echo time $(\mathrm{TE})=66 \mathrm{~ms}$; flip angle $(\mathrm{FA})=90^{\circ}$; matrix size $=128 \times 128$; voxel dimensions $=$ $1.4 \mathrm{~mm} \times 1.4 \mathrm{~mm} \times 4 \mathrm{~mm}$ ) with an interscan temporal spacing of $5 \mathrm{~s}$. Each functional time-series consisted of five "resting" volumes ( $25 \mathrm{~s}$, discarded from further analysis) followed either by 72 acquisitions during which the experimental conditions were periodically alternated every eight acquisitions (see Section 2.3).

After the functional acquisitions, a high resolution threedimensional data set covering the whole brain (referred to as three-dimensional anatomical image), was collected for each subject with a three-dimensional T1-weighted fast low-angle shot (FLASH) (matrix $=256 \times 256$; thickness $=1 \mathrm{~mm}$, number of partitions $=170-180$; voxel dimensions $=1 \mathrm{~mm} \times 1 \mathrm{~mm} \times 1 \mathrm{~mm})$ sequence. These three-dimensional recordings were used for polygon mesh reconstruction of the grey/white matter boundary of the subjects' brains [18] and cortex-based statistical analysis (see Section 2.4.2).

\subsubsection{Data analysis}

The fMRI data processing was performed using BrainVoyager $3.0[7,10,11]$. Prior to statistical analysis, the time series of functional images were aligned for each slice in order to minimise the signal changes related to small motions of the subject during the acquisition. Spatial filtering of functional time series was performed by convolution of each EPI-image with a two-dimensional Gaussian smoothing kernel with full width at half maximum (FWHM) = $2.8 \mathrm{~mm} \times 2.8 \mathrm{~mm}$. Temporal filtering of functional time series included removal of the linear drifts of the signal with respect to time from each voxel's time-course and low-pass filtering of each voxel's time-course with a one-dimensional Gaussian filter with FWHM $=10 \mathrm{~s}$.

After these pre-processing steps, each complete functional time-series was interpolated to $3 \mathrm{~mm} \times 3 \mathrm{~mm} \times 3 \mathrm{~mm}$ (nominal) spatial resolution, co-registered to the three-dimensional anatomical volume and normalised into Talairach space [29] following procedures described elsewhere [7,31]. This yielded a four-dimensional data representation (volume time course or VTC) for each functional data set that, being co-registered to the three-dimensional anatomy, was also co-registered to the polygon mesh representing the cortical sheet. This mesh was projected into the functional data set and the voxels that were within a specified range were tagged as "cortex". All the following steps of statistical analysis were limited to these cortical voxels.

The general linear model (GLM) of the experiment was computed from the 21 (7 subjects, 3 sessions per subject) VTCs. The signal values during the categorical imagery, coordinate imagery, and syllable counting conditions were considered the effects of interest. The global level of the signal time-courses in each session was considered to be a confounding effect. To analyse the effects of conditions compared to baseline and contrasts between conditions, three-dimensional individual and group statistical maps were generated by associating each tagged voxel with the $F$-value corresponding to the specified set of predictors and calculated on the basis of the least squares solution of the GLM. Effects were only accepted as significant when the associated $P$-value yielded $P^{\prime}=P N<0.001$, where $N$ represented the number of independent statistical tests. In single-subject analysis, $N$ was chosen as the total number of cortical voxels (i.e. indexed from the surface mesh, about $28,000)$ and the uncorrected $P$ threshold was adequately adjusted in order to keep the corrected $P^{\prime}$ threshold at $10^{-3}$. In multi-subject analysis, $N$ was chosen as the number of voxels resulting from the logic OR of the individual surface meshes. This procedure provided an effective means of nonparametrically adjusting for multiple comparisons while preserving from an excessive loss of statistical power of the conventional Bonferroni approach [12].

Statistical results were then visualised through projecting three-dimensional statistical maps on surface reconstruction of the cortical sheet. In the contrast maps (Fig. 1A and B), the colour scale (red-to-yellow) codes the significance level. In the relative contribution (RC) maps (Fig. 1C-E, Fig. 2) the $\mathrm{RC}$ of the two selected conditions in explaining the variance of a voxel time course were computed as $\mathrm{RC}=\left(b_{1}-\right.$ $\left.b_{2}\right) /\left(b_{1}+b_{2}\right)$, where $b_{i}$ is the standardised regression coefficient corresponding to condition $i$. The RC index was visualised with a red-yellow-blue-green pseudo-colour scale. An $\mathrm{RC}$ value of 1 (red) indicates that a voxel time course is solely explained with predictor 1 whereas an $\mathrm{RC}$ value of -1 (green) indicates that a voxel time course is explained solely with predictor 2 . An $\mathrm{RC}$ value of 0 indicates that a voxel time course is explained with an equal contribution of both predictor sets. Only RC values greater than 0.7 were visualised.

To evaluate lateralisation of hemispheric activation during the coordinate and the categorical task, we calculated the number of activated voxels in anatomical regions where bilateral activation was observed on individual maps. The statistical comparison between the number of voxels activated in either task in the two hemispheres across the seven subjects was made by Wilcoxon signed rank test, a non-parametric equivalent of paired $t$-test. 


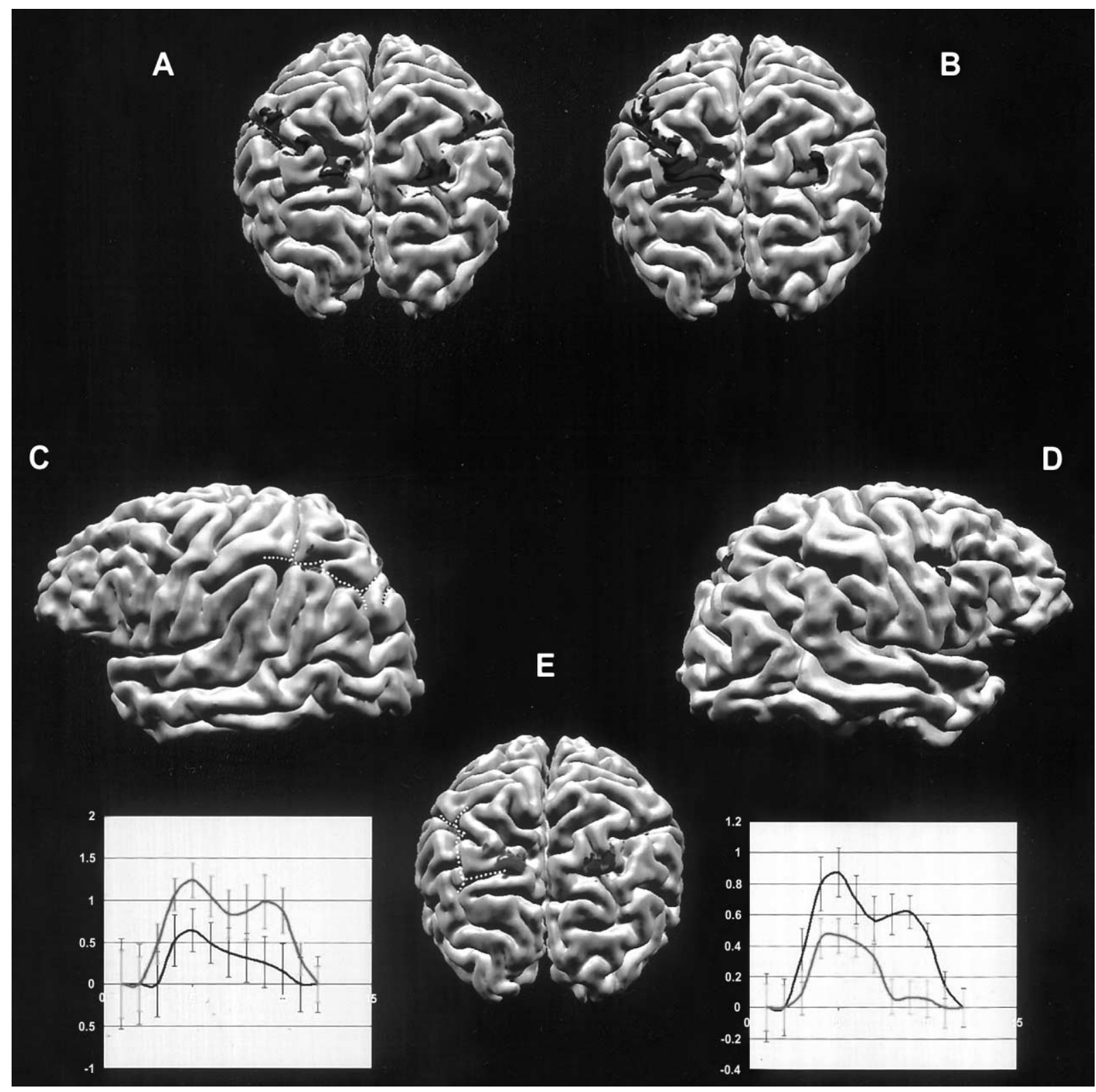

Fig. 1. Multi-subject GLM contrast maps $\left(P^{\prime}<0.001\right.$, corrected) superimposed on a three-dimensional reconstruction of the cortical surface of an individual normalized three-dimensional anatomy. The upper panel (posterior view; the left hemisphere is represented on the left side) shows the activation produced by the coordinate (A) and the categorical (B) spatial task, when compared to the control task: both imagery tasks mainly activated the SPL bilaterally. The lower panel (C: left lateral view; D: right lateral view; E: posterior view, left hemisphere on left side) shows the RC map between the coordinate (in blue) and the categorical (in yellow) spatial tasks. The coordinate task produced a higher activation in the right SPL; the categorical task activated mainly the left SPL. The "bold" signal time courses from all the activated voxels in the SPL of each hemisphere, averaged across subjects and epochs, are shown in the respective bottom corners. On the left side, the averaged signal time-course reveals a higher percent signal change in the categorical task (yellow line) than in the coordinate task (blue line); a reverse pattern is observed on the right side. Other foci of activation are present in the both the angular gyri for both the tasks and in the right prefrontal cortex (coordinate task). In $\mathrm{C}$ and $\mathrm{E}$, the white dotted line corresponds to the intraparietal sulcus and its main branches; the red dotted line corresponds to the parieto-occipital fissure.

\subsubsection{Eye movements}

In two subjects, the experiment was performed under eye movement monitoring. We used the fMRI compatible Ober2 (Permobil Meditech, Timra, Sweden) infrared eye tracking system [1], sampling the horizontal and vertical positions of both eyes at $120 \mathrm{~Hz}$.

\section{Results}

\subsection{Behavioural results}

The syllable counting task proved to be the most difficult task, while the categorical and the coordinate spatial 


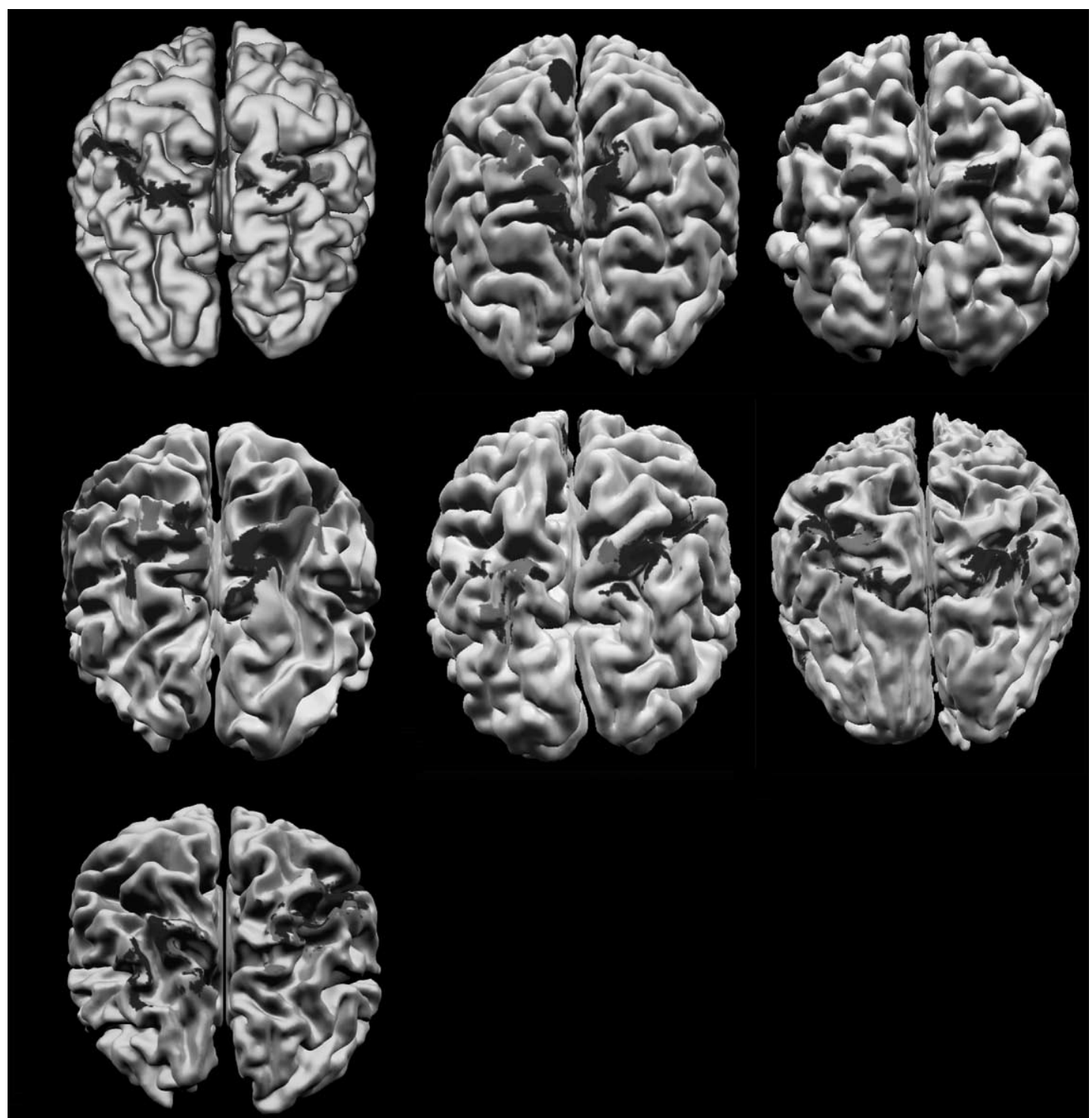

Fig. 2. RC maps $\left(P^{\prime}<0.001\right.$, corrected) of the coordinate (in blue) and the categorical (in yellow) spatial task superimposed on mesh reconstruction of the cortical surface of all seven subjects (posterior view; the left hemisphere is represented on the left side). Four subjects showed larger left hemisphere activation in the categorical task than in the coordinate task, while in the remaining subjects no clear lateralisation was found (see also Fig. 3).

judgements determined very similar number of correct responses and mean correct reaction times. The differences among the three experimental conditions were not statistically significant (Table 1 ).
The two subjects in whom eye movements were monitored could maintain stable fixation on the central point during the whole experiment, with less than five eye movements of $1^{\circ}$ or more per subject during all the experimental conditions.

Table 1

Behavioural results

\begin{tabular}{lllll}
\hline & \multicolumn{2}{l}{ Correct responses $(\%)$} & & \multicolumn{2}{c}{ Correct reaction times } \\
\cline { 2 - 3 } \cline { 5 - 5 } & Mean & S.E. & Mean & \multicolumn{2}{c}{ S.E. } \\
\hline Coordinate judgement & 84.7 & 1.7 & 2446.514 & 77.531 \\
Categorical judgement & 86.7 & 1.3 & 2475.943 & 64.83 \\
Syllable counting & 83.1 & 2.9 & 2723.143 & 119.65 \\
\hline
\end{tabular}

Differences among tasks were not statistically significant (for correct responses: $H=2.61, P=0.27$; for reaction times: $H=4.14, P=0.13$ ). 
Table 2

Location and extension of contrasts between the coordinate and the categorical condition

\begin{tabular}{|c|c|c|c|c|c|c|c|c|c|c|}
\hline & \multirow[t]{2}{*}{$\mathrm{BA}$} & \multirow[t]{2}{*}{ Side } & \multicolumn{4}{|c|}{ Coordinate judgement } & \multicolumn{4}{|c|}{ Categorical judgement } \\
\hline & & & $x$ & $y$ & $z$ & Size & $x$ & $y$ & $z$ & Size \\
\hline SPL & 7 & $\begin{array}{l}\text { Left } \\
\text { Right }\end{array}$ & $\begin{array}{r}-17 \\
21\end{array}$ & $\begin{array}{l}-71 \\
-67\end{array}$ & $\begin{array}{l}53 \\
48\end{array}$ & $\begin{array}{r}67 \\
782\end{array}$ & $\begin{array}{r}-15 \\
15\end{array}$ & $\begin{array}{l}-71 \\
-71\end{array}$ & $\begin{array}{l}49 \\
53\end{array}$ & $\begin{array}{r}624 \\
58\end{array}$ \\
\hline Angular gyrus & 40 & $\begin{array}{l}\text { Left } \\
\text { Right }\end{array}$ & $\begin{array}{r}-41 \\
37\end{array}$ & $\begin{array}{l}-38 \\
-45\end{array}$ & $\begin{array}{l}39 \\
45\end{array}$ & $\begin{array}{l}63 \\
64\end{array}$ & $\begin{array}{r}-49 \\
46\end{array}$ & $\begin{array}{l}-48 \\
-47\end{array}$ & $\begin{array}{l}45 \\
44\end{array}$ & $\begin{array}{r}104 \\
56\end{array}$ \\
\hline Inferior frontal sulcus & $9 / 44$ & Right & 37 & 13 & 38 & 136 & & & & \\
\hline
\end{tabular}

The position of each area is given as the Talairach coordinates of the centre of mass of supra-threshold clusters $(P<0.001$, corrected $)$ of the group analysis.

\subsection{The fMRI results}

The contrasts between the categorical and the coordinate spatial imagery tasks with the control task yielded similar, but not overlapping, cortical activation patterns. Both spatial imagery tasks activated the superior parietal lobule (SPL) bilaterally. Moreover, activated cortical areas were also seen along the anterior part of the intraparietal sulcus, extending into the inferior parietal lobule bilaterally in the coordinate task, and only on the left side in the categorical task (Fig. 1A and $\mathrm{B}$ ).

The RC maps of the spatial imagery tasks (Fig. 1C-E) suggested that the categorical and the coordinate processing of spatial mental images shared a common region of activation in the SPL, but with some differences between each other. The areas in the SPL showed a relatively lateralised pattern of activation, with a higher (but not exclusive) contribution of the right side during the coordinate task, and a higher contribution of the left during the categorical task (see also time courses in Fig. 1). Both tasks activated the angular gyrus bilaterally, in the depth of the anterior part of intraparietal sulcus; the activation induced by the categorical task produced a larger cluster size on the left side (Table 2). Moreover, the coordinate task specifically induced activation of the right prefrontal cortex encroaching upon the posterior end of the inferior frontal sulcus.

The analysis of single subjects' activations confirmed the robust finding that the SPLs were engaged in both spatial imagery tasks (Fig. 2). As regards the pattern of relative lateralisation within the SPLs, four out of seven subjects showed larger left hemisphere activation in the categorical task than in the coordinate task, and five of seven subjects showed larger right hemisphere activation in the coordinate task than in the categorical task. Considering the whole parietal lobes, the total number of activated voxels did not differ between the two hemispheres (Wilcoxon $Z=1.16, P=0.24$ ) or between the two tasks across the seven subjects (Wilcoxon $Z=1.54, P=0.12$ ); the mean percent number of activated voxels (Fig. 3) did not differ between the two tasks in the left parietal lobe (Wilcoxon $Z=0.17, P=0.87$ ), while it was significantly higher in the coordinate task than

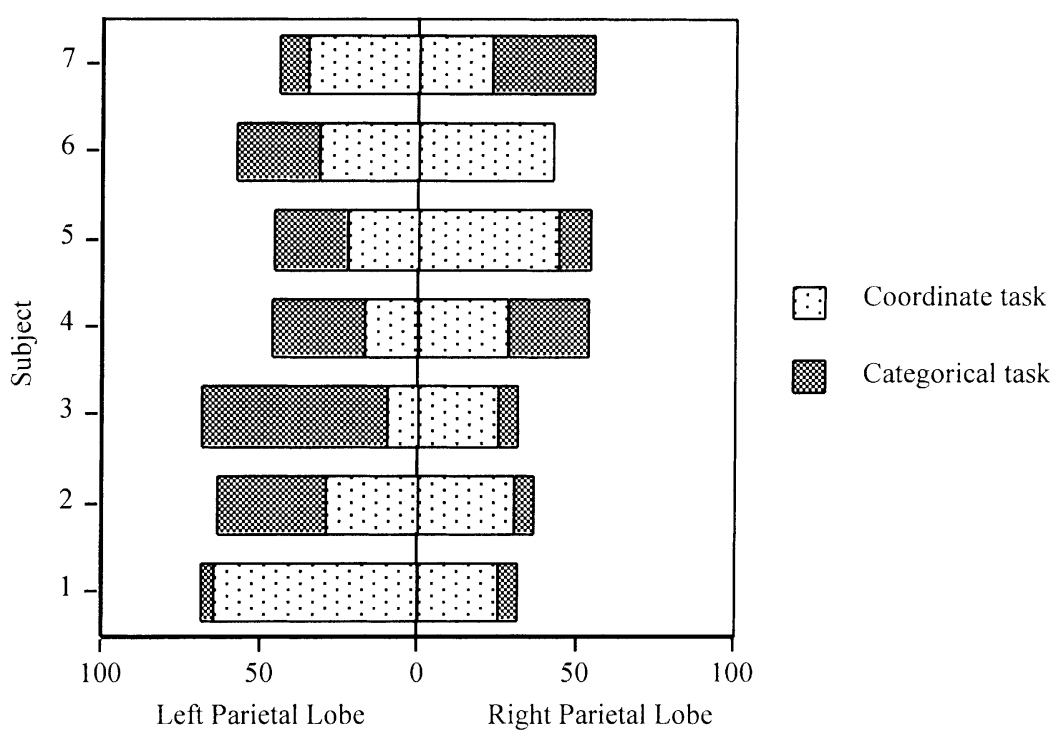

Fig. 3. Percent number of activated voxels during the coordinate and the categorical tasks in the left (leftward from the origin) and in the right (rightward from the origin) parietal lobe in the seven subjects (percentages calculated on the total number of voxels activated within both parietal lobes of each subject). 
in the categorical task in the right parietal lobe (Wilcoxon $Z=2.03, P=0.04$ ).

\section{Discussion}

The parietal lobes are strongly involved in the processing of spatially-coded material. Several fMRI studies have shown that spatial processing of visual or tactile stimuli activate the posterior parietal cortex [10,27]. Recently, we demonstrated that closely matching regions along the intraparietal sulcus are bilaterally activated during spatial mental imagery and visual perception [31]. On the basis of these findings we could substantiate the idea that within the SPL a spatial transformation area [11] is activated during visual perception and mental imagery tasks.

In the present paper we aimed to study cortical activation during categorical and coordinate spatial processing of mental images. For this purpose, we adopted a well-established experimental paradigm [20] and modified it to ensure that subjects had to generate visual mental images in order to solve the task. For the coordinate judgement we required subjects to match metrical properties of two different times imagined on analogue clock faces; this task proved to evoke a robust pattern of cortical activation [31]. For the categorical judgement we asked to imagine the same kind of stimuli and to judge whether both hands lay in the cued half of an analogue clock face at a given time: care was taken to include four possible cues and to provide the cue after the generation of mental images, in order to minimise the use of verbal strategies. Both tasks share several cognitive processes: auditory processing of verbal instructions, image generation, image maintenance and scanning, and response selection procedures. The comparison between the two tasks and that between each task and a third experimental condition employing the same verbal material and a comparable working memory load, should reveal whether the posterior parietal cortex is involved in both kinds of spatial processing and whether any lateralisation of cortical activation corresponds to the categorical/coordinate dichotomy in the imagery domain.

Our results showed that categorical and coordinate spatial judgements on imagined stimuli rely on the activation of a set of cortical areas, mainly centred upon the SPLs. While these data confirm the involvement of the posterior parietal cortex in spatial processing, they also point to a functional involvement of interconnected neural networks according to cognitive requirements of different spatial tasks. The areas activated by the two tasks in the SPL closely match those reported in several studies on mental imagery, mental rotation and other spatial tasks $([13,14]$; for a meta-analysis see [31]), more rostrally than those recently shown to be involved in object manipulation ([3]; see [24] for a discussion of the role of the SPL in space perception).

Moreover, the coordinate judgement specifically relied on the activation of the right prefrontal cortex. The dorsal prefrontal cortex has been demonstrated to be involved in maintenance and manipulation of information $[6,15,23,26]$. In studies on visual and spatial mental imagery the coactivation of frontal and parietal areas has been reported very often and related to image generation or to image maintenance $[13,19,30]$. Since behavioural results of our experiment demonstrate that the categorical and the coordinate imagery tasks had equivalent processing load, the differential activation of right prefrontal cortex could be explained by a higher processing load on spatial working memory during the coordinate task [28].

With respect to the issue of lateralisation of categorical and coordinate spatial judgements. Baciu et al. [2] showed a stronger activation of the left than of the right angular gyrus in a categorical task, and the reverse pattern of lateralisation in a coordinate task in the visual perception domain. However, Baciu et al. did not study the entire neural network involved in the tasks nor did they verify whether the same lateralisation of cortical activation was present in other brain regions. Our findings are quite congruent with the data of Baciu et al., but our whole-brain study allowed us to verify that some degree of relative lateralisation may be found both in the parietal cortex and in other cortical regions activated by the two imaginal spatial tasks. Therefore, the hemispheric predominance in psychometric measures may be related to several anatomo-functional correlates. As well as in psychometric studies [20], it has to be considered that the observed differences in the cortical activation might originate at different stages of the cognitive processes involved in the tasks. For example, it could be argued that the requirement of the coordinate judgement would elicit an image generation process more heavily dependent on precise metric assembling of multi-part mental images, whereas the categorical judgement could induce a global, sketchy reconstruction of mental images [20]. Alternatively, it could be hypothesised that generating a multi-part mental image requires a metric spatially-organised arrangement of its constituent, a cognitive step common to the two imagery tasks, and that the observed differences in cortical activation could arise during different spatial computations required by the categorical or the coordinate judgement. Novel experimental paradigms would be necessary to differentiate among possible theoretical explanations of our findings. For instance, the coordinate/categorical distinction could be assessed in an experimental set including two parallel visual perceptual conditions for the categorical and the coordinate judgement. However, this would imply several methodological drawbacks, since such perceptual tasks would be considerably easier that the imagery conditions, as has been stated in previous studies [9] and verified during an our own fMRI experiment [31]. Further manipulations of experimental conditions should be required to render the perceptual tasks of equivalent difficulty with respect to imagery tasks. With these caveats in mind, we can suggest that the task-dependent patterns of cortical activation described in the present paper cannot be ascribed to one or the other cognitive process 
with certainty. Other experimental approaches, for example by means of event-related fMRI paradigms, would be necessary to disentangle cortical regions respectively involved in the generation of mental images, common to the present two tasks, or in subsequent spatial judgements.

In conclusion, the present findings support the idea that the SPLs are crucial for both categorical and coordinate spatial judgements. These regions, together with other parietal and prefrontal areas, showed a pattern of relative lateralisation, since the left hemisphere was more involved in the categorical task, while the coordinate task elicited activation of more extended regions of the right hemisphere and of regions thought to be involved in spatial working memory tasks [21,32]. As in the visual perception domain [2], our findings would be in agreement with Kosslyn's [16] theory. The possible generalisation of our finding is limited however by the small sample of volunteers and by the fixed effects analysis used in the GLM of the present experiments. Actually, it should be reminded that individual and sexual factors can affect the pattern of lateralisation, although recent studies did not demonstrate sexual differences in the lateralisation of spatial abilities [8]. Therefore, adopting a conservative position, we can conclude that different interconnected neural networks are activated to comply with specific test requirements of our imaginal spatial tasks, giving rise to functional imaging patterns that are compatible with psychological theories on hemispheric specialisation.

\section{Acknowledgements}

We are grateful to two anonymous referees for their valuable comments on the manuscript.

\section{References}

[1] Aisenberg S. Measurement and analysis of binocular rapid eye movement, including saccades, saccadic prediction, fixations, nystagmus, and smooth pursuit. Investigations in Ophthalmology and Vision Sciences 1996;Suppl 37:S274.

[2] Baciu M, Koenig O, Vernier MP, Bedoin N, Rubin C, Segebarth C. Categorical and coordinate spatial relations: fMRI evidence for hemispheric specialization. Neuroreport 1999;10:1373-8.

[3] Binkofski F, Buccino G, Posse S, Seitz RJ, Rizzolatti G, Freund H. A fronto-parietal circuit for object manipulation in man: evidence from an fMRI-study. European Journal of Neurosciences 1999;11: 3276-86.

[4] Brown HD, Kosslyn SM. Cerebral lateralization. Current Opinion in Neurobiology 1993;3:183-6.

[5] Bruyer R, Scailquin JC, Coibion P. Dissociation between categorical and coordinate spatial computations: modulation by cerebral hemispheres, task properties, mode of response, and age. Brain and Cognition 1997;33:245-77.

[6] D'Esposito M, Postle BR, Ballard D, Lease J. Maintenance versus manipulation of information held in working memory: an eventrelated fMRI study. Brain and Cognition 1999;41:66-86.

[7] Dierks T, Linden DEJ, Jandl M, Formisano E, Goebel R, Lanfermann H, Singer W. Activation of Heschl's gyrus during auditory hallucination. Neuron 1999;22:615-21.
[8] Dietrich T, Krings T, Neulen J, Willmes K, Erberich S, Thron A, et al. Effects of blood estrogen level on cortical activation patterns during cognitive activation as measured by functional MRI. Neuroimage 2001;13:425-31.

[9] French CC, Painter J. Spatial processing of images and hemisphere function. Cortex 1991;27:511-20.

[10] Goebel R, Khorram-Sefat D, Muckli L, Hacker H, Singer W. The constructive nature of vision: direct evidence from functional magnetic resonance imaging studies of apparent motion and motion imagery. European Journal of Neurosciences 1998;10:1563-73.

[11] Goebel R, Linden DEJ, Lanfermann H, Zanella FE, Singer W. Functional imaging of mirror and inverse reading reveals separate coactivated networks for oculomotion and spatial transformations. Neuroreport 1998;9:713-9.

[12] Goebel R, Singer W. Cortical surface-based statistical analysis of functional magnetic resonance imaging data. Neuroimage 1999;9: S64.

[13] Ishai A, Ungerleider LG, Haxby JV. Distributed neural systems for the generation of visual images. Neuron 2000;28:979-90.

[14] Knauff M, Kassubek J, Mulack T, Greenlee MW. Cortical activation evoked by visual mental imagery as measured by fMRI. Neuroreport 2000;11:3957-62.

[15] Koechlin E, Corrado G, Pietrini P, Grafman J. Dissociating the role of the medial and lateral anterior prefrontal cortex in human planning. Proceedings of the National Academy of Sciences USA 2000;97:7651-6.

[16] Kosslyn SM. Seeing and imaging in the cerebral hemispheres: a computational approach. Psychological Review 1987;94:148-75.

[17] Kosslyn SM, Maljkovic V, Hamilton SE, Horwitz G, Thompson WL. Two types of image generation: evidence for left and right hemisphere processes. Neuropsychologia 1995;33:1485-510.

[18] Kriegeskorte N, Goebel R. An efficient algorithm for topologically correct segmentation of the cortical sheet in anatomical $\mathrm{mr}$ volumes. Neuroimage 2001;14:329-46.

[19] Mellet E, Petit L, Mazoyer B, Denis M, Tzourio N. Reopening the mental imagery debate: lessons from functional anatomy. Neuroimage 1998;8:129-39.

[20] Michimata C. Hemispheric processing of categorical and coordinate spatial relations in vision and visual imagery. Brain and Cognition 1997;33:370-87.

[21] Ng VWK, Eslinger PJ, Williams SCR, Brammer MJ, Bullmore ET, Andrew CM, et al. Hemispheric preference in visuospatial processing: a complementary approach with fMRI and lesion studies. Human Brain Mapping 2000;10:80-6.

[22] Parrot M, Doyon B, Demonet JF, Cardebat D. Hemispheric preponderance in categorical and coordinate visual processes. Neuropsychologia 1999;37:1215-25.

[23] Petrides M. Mapping prefrontal cortical systems for the control of cognition. In: Toga AW, Mazziotta JC, editors. Brain mapping. The systems. San Diego: Academic Press, 2000. pp. 535-60.

[24] Rizzolatti G, Fogassi L, Gallese V. Parietal cortex: from sight to action. Current Opinion in Neurobiology 1997;7:562-7.

[25] Roth EC, Hellige JB. Spatial processing and hemispheric asymmetry. Contributions of the transient/magnocellular visual system. Journal of Cognitive Neurosciences 1998;10:472-84.

[26] Rowe JB, Toni I, Josephs O, Frackowiak RSJ, Passingham RE. The prefrontal cortex: response selection or maintenance within working memory? Science 2000;288:1656-60.

[27] Sathian K, Zangaladze A, Hoffmann JM, Grafton ST. Feeling with the mind's eye. Neuroreport 1997;8:3877-81.

[28] Smith EE, Jonides J. Storage and executive processes in the frontal lobes. Science 1999;283:1657-61.

[29] Talairach J, Tournoux P. Co-planar stereotaxic atlas of the human brain: three-dimensional proportional system: an approach to cerebral imaging. Stuttgart: Thieme, 1988.

[30] Thompson WL, Kosslyn SM. Neural systems activated during visual mental imagery. A review and meta-analyses. In: Toga AW, Mazziotta 
JC, editors. Brain mapping. The systems. San Diego: Academic Press, 2000. pp. 535-60.

[31] Trojano L, Grossi D, Linden DEJ, Formisano E, Hacker H, Zanella FE, et al. Matching two imagined clocks: the functional anatomy of spatial analysis in the absence of visual stimulation. Cerebral Cortex 2000;10:473-81.
[32] Ungerleider LG, Courtney SM, Haxby JV. A neural system for human visual working memory. Proceedings of National Academic Science USA 1998;95:883-90.

[33] Wilkinson D, Donnelly N. The role of stimulus factors in making categorical and coordinate spatial judgements. Brain and Cognition 1999;39:171-85. 